\title{
Procedures of Translating Culture-Specific Concepts
}

\author{
Phd. Canditate Morena Braçaj
}

\author{
Albanian College Durres, Albania
}

Email: morenacitozi@yahoo.com

\section{Doi:10.5901/mjss.2015.v6n1s1p476}

\begin{abstract}
Translating culture-specific concepts seem to be one of the most challenging tasks to be performed by a translator; in other words, culture and intercultural awareness, are far more complex phenomena than it may seem to the translator. The more a translator is aware of complexities of differences between cultures, the better a translator s/he will be. It is probably right to say that there has never been a time translators were unaware of cultural differences and their significance for translation. Translation theorists have been aware of the problems of cultural knowledge and cultural differences at least since ancient Rome. Cultural knowledge and cultural differences have been a major focus of translator training and translation theory for as long as either has been in existence. The present paper aims to present some procedures and strategies of translating cultural concepts by different theorists, which might help translators during the translation process and make them choose the procedures that seem to be more effective than the others.
\end{abstract}

Keywords: culture-specific concept, procedures, cultural gap, SL, TL.

\section{Introduction}

The main concern has traditionally been with words and phrases that are so heavily grounded in one culture that they are almost impossible to translate into the terms -verbal or otherwise - of another. Long debate have been held over when to paraphrase, when to use the nearest equivalent, when to coin a new word by translating literally, and when to transcribe. All these "untranslatable" cultural-bound words and phrases continued to fascinate translators and translation theorists. The first theory developed in this field was introduced by Mounin in 1963 who underlined the importance of the signification of a lexical item claiming that only if this notion is considered will the translated item fulfill its function correctly. The problem with this theory is that all the cultural elements do not involve just the items, what a translator should do in the case of cultural implications which are implied in the background knowledge of SL readers? The notion of culture is essential to considering the implications for translation and, despite the differences in opinion as to whether language is part of culture or not, the two notions of culture and language appear to be inseparable. In 1964, Nida discussed the problems of correspondence in translation, conferred equal importance to both linguistic and cultural differences between the SL and the TL and concluded that differences between cultures may cause more severe complications for the translator than do differences in language structure. It is further explained that parallels in culture often provide a common understanding despite significant formal shifts in the translation. According to him cultural implications for translation are thus of significant importance as well as lexical concerns.Nida's definitions of formal and dynamic equivalence in 1964 considers cultural implications for translation. According to him, a "gloss translation" mostly typifies formal equivalence where form and content are reproduced as faithfully as possible and the TL reader is able to "understand as much as he can of the customs, manner of thought, and means of expression" of the SL context. Contrasting with this idea, dynamic equivalence "tries to relate the receptor to modes of behavior relevant within the context of his own culture" without insisting that he "understand the cultural patterns of the source-language context". According to him problems may vary in scope depending on the cultural and linguistic gap between the two (or more) languages concerned.

It can be said that the first concept in cultural translation studies was cultural turn that in 1978 was presented by the work on Polysystems and translation norms by Even-Zohar and in 1980 by Toury. They dismiss the linguistic kinds of theories of translation and refer to them as having moved from word to text as a unit but not beyond. They themselves go beyond language and focus on the interaction between translation and culture, on the way culture impacts and constraints translation and on the larger issues of context, history and convention. Therefore, the move from translation as a text to translation as culture and politics is what they call it a Cultural Turn in translation studies and became the ground for a metaphor adopted by Bassnett and Lefevere in 1990. In fact Cultural Turn is the metaphor adopted by 
Cultural Studies oriented translation theories to refer to the analysis of translation in its cultural, political, and ideological context. Since 1990, the turn has extended to incorporate a whole range of approaches from cultural studies and is a true indicator of the interdisciplinary nature of contemporary translation studies. Translation typically has been used to transfer written or spoken SL texts to equivalent written or spoken TL texts. In general, the purpose of translation is to reproduce various kinds of texts-including religious, literary, scientific, and philosophical texts-in another language and thus making them available to wider readers. If language were just a classification for a set of general or universal concepts, it would be easy to translate from an SL to a TL; furthermore, under the circumstances the process of learning an L2 would be much easier than it actually is. In this regard, Culler (1976) believes that languages are not nomenclatures and the concepts of one language may differ radically from those of another, since each language articulates or organizes the world differently, and languages do not simply name categories; they articulate their own (p.21-2). This paper aims to present the differences and the challenges that exist between source language and target one and the variation in their cultures make the process of translating difficult to cope with. Among the problematic factors involved in translation such as form, meaning, style, proverbs, idioms, etc., translators many times find themselves coping with cultural concepts, which make their work even harder. Therefore, the present paper is going to concentrate mainly on the procedures of translating CSCs in general so that they can help translators to solve the problems during the process of translating. Thus, translators, during the analysis of the source text, should be able to identify which of these procedures and strategies of translating culture-specific concepts seem to be more effective than the others and can be useful for that particular passage. Moreover, translators should know how not to deprive target readers of enjoying the text as it is in the orginal one.

\subsection{Research methods.}

This study is a descriptive research and its aim is to carry out an analysis of particular strategies applied to cope with specific cultural concepts and to present which strategies are more frequent and can help the translator to solve such challenges during translation process. This paper is chosen because in translating culture specific concepts and the translators always face many problems. Thus, it decides to look at this problem carefully in order to find a way for having a good translation. There are no two languages identical to each other; thus, the translators have difficulties in finding the appropriate equivalent related to culture concept and they need to be aware of such procedures so that they can help them conveying the culture from source to target language.

\subsection{Research questions}

1. What are some strategies that a translator should know in order to translate concepts in a specific culture?

2. How can translators cope with cultural concepts and how can they make use of these strategies in different situations?

\subsubsection{Procedures of translating culture-specific concepts (CSCs)}

Graedler (2000:3) puts forth some procedures of translating CSCs:

1. Making up a new word.

2. Explaining the meaning of the SL expression in lieu of translating it.

3. Preserving the SL term intact.

4. Opting for a word in the TL which seems similar to or has the same "relevance" as the SL term.

Defining culture-bound terms (CBTs) as the terms which "refer to concepts, institutions and personnel which are specific to the SL culture" (p.2), Harvey (2000:2-6) puts forward the following four major techniques for translating CBTs:

1. Functional Equivalence: It means using a referent in the TL culture whose function is similar to that of the source language (SL) referent. As Harvey (2000:2) writes, authors are divided over the merits of this technique: Weston (1991:23) describes it as "the ideal method of translation," while Sarcevic (1985:131) asserts that it is "misleading and should be avoided."

2. Formal Equivalence or 'linguistic equivalence': It means a 'word-for-word' translation.

3. Transcription or 'borrowing' (i.e. reproducing or, where necessary, transliterating the original term): It stands at the far end of SL-oriented strategies. If the term is formally transparent or is explained in the context, it may be used alone. In other cases, particularly where no knowledge of the SL by the reader is presumed, transcription is accompanied by an explanation or a translator's note. 
4. Descriptive or self-explanatory translation: It uses generic terms (not CBTs) to convey the meaning. It is appropriate in a wide variety of contexts where formal equivalence is considered insufficiently clear. In a text aimed at a specialized reader, it can be helpful to add the original SL term to avoid ambiguity.

The following are the different translation procedures that Newmark (1988b) proposes:

$>$ Transference: it is the process of transferring an SL word to a TL text. It includes transliteration and is the same as what Harvey (2000:5) named "transcription."

Naturalization: it adapts the SL word first to the normal pronunciation, then to the normal morphology of the TL. (Newmark, 1988b:82)

$>$ Cultural equivalent: it means replacing a cultural word in the SL with a TL one. however, "they are not accurate" (Newmark, 1988b:83)

$>$ Functional equivalent: it requires the use of a culture-neutral word. (Newmark, 1988b:83)

> Descriptive equivalent: in this procedure the meaning of the CBT is explained in several words. (Newmark, 1988b:83)

> Componential analysis: it means "comparing an SL word with a TL word which has a similar meaning but is not an obvious one-to-one equivalent, by demonstrating first their common and then their differing sense components." (Newmark, 1988b:114)

$>$ Synonymy: it is a "near TL equivalent." Here economy trumps accuracy. (Newmark, 1988b:84)

$>$ Through-translation: it is the literal translation of common collocations, names of organizations and components of compounds. It can also be called: calque or loan translation. (Newmark, 1988b:84)

$>$ Shifts or transpositions: it involves a change in the grammar from SL to TL, for instance, (i) change from singular to plural, (ii) the change required when a specific SL structure does not exist in the TL, (iii) change of an SL verb to a TL word, change of an SL noun group to a TL noun and so forth. (Newmark, 1988b:86)

> Modulation: it occurs when the translator reproduces the message of the original text in the TL text in conformity with the current norms of the TL, since the SL and the TL may appear dissimilar in terms of perspective. (Newmark, 1988b:88) - Recognized translation: it occurs when the translator "normally uses the official or the generally accepted translation of any institutional term." (Newmark, 1988b:89)

$>$ Compensation: it occurs when loss of meaning in one part of a sentence is compensated in another part. (Newmark, 1988b:90)

$>$ Paraphrase: in this procedure the meaning of the CBT is explained. Here the explanation is much more detailed than that of descriptive equivalent. (Newmark, 1988b:91)

$>$ Couplets: it occurs when the translator combines two different procedures (Newmark,1988b:91)

$>$ Notes: notes are additional information in a translation. (Newmark, 1988b:91)

Notes can appear in the form of 'footnotes.' Although some stylists consider a translation sprinkled with footnotes terrible with regard to appearance, nonetheless, their use can assist the TT readers to make better judgments of the ST contents. Nida (1964:237-39) advocates the use of footnotes to fulfill at least the two following functions: (i) to provide supplementary information, and (ii) to call attention to the original's discrepancies.

\subsection{Non-equivalents}

In 1992, Mona Baker stated that S.L word may express a concept which is totally unknown in the target culture. It can be abstract or concrete. It maybe a religious belief, a social custom or even a type of food. In her book, In Other Words, she argued about the common non-equivalents to which a translator come across while translating from SL into TL, while both languages have their distinguished specific culture. She put them in the following order:

a) Culture specific concepts

b) The SL concept which is not lexicalized in TL

c) The SL word which is semantically complex

d) The source and target languages make different distinction in meaning

e) The TL lacks a super ordinate

f) The TL lacks a specific term (hyponym)

g) Differences in physical or interpersonal perspective

h) Differences in expressive meaning 


\subsection{The categorization of cultural words by Newmark}

In 1988 Newmark defined culture as "the way of life and its manifestations that are peculiar to a community that uses a particular language as its means of expression", thus acknowledging that each language group has its own culturally specific features. He also introduced 'Cultural word' which the readership is unlikely to understand and the translation strategies for this kind of concept depend on the particular text-type, requirements of the readership and client and importance of the cultural word in the text.

Peter Newmark also categorized the cultural words as follows:

1) Ecology: flora, fauna, hills, winds, plains

2) Material Culture: food, clothes, houses and towns, transport

3) Social Culture: work and leisure

4) Organizations Customs, Activities, Procedures,

Concepts:

- Political and administrative

- Religious

- Artistic

5) Gestures and Habits

He introduced contextual factors for translation process which include:

1- Purpose of text

2- Motivation and cultural, technical and linguistic level of readership

3- Importance of referent in SL text

4- Setting (does recognized translation exist?)

5- Recency of word/referent

6- Future or refrent.

He further clearly stated that operationally he does not regard language as a component or feature of culture in direct opposition to the view taken by Vermeer who stated that "language is part of a culture" (1989:222). According to Newmark, Vermeer's stance would imply the impossibility to translate whereas for the latter, translating the source language (SL) into a suitable form of TL is part of the translator's role in transcultural communication. Language and culture may thus be seen as being closely related and both aspects must be considered for translation. When considering the translation of cultural words and notions, Newmark proposed two opposing methods: transference and componential analysis. According to him transference gives "local colour," keeping cultural names and concepts. Although placing the emphasis on culture, meaningful to initiated readers, he claimed this method may cause problems for the general readership and limit the comprehension of certain aspects. The importance of the translation process in communication led Newmark to propose componential analysis which he described as being "the most accurate translation procedure, which excludes the culture and highlights the message".

Some strategies introduced by Newmark for dealing with cultural gap:

1) Naturalization:

A strategy when a SL word is transferred into TL text in its original form.

2) Couplet or triplet and quadruplet:

Is another technique the translator adopts at the time of transferring, naturalizing or calques to avoid any misunderstanding: according to him it is a number of strategies combine together to handle one problem.

3) Neutralization:

Neutralization is a kind of paraphrase at the level of word. If it is at higher level it would be a paraphrase. When the SL item is generalized (neutralized) it is paraphrased with some culture free words.

4) Descriptive and functional equivalent:

In explanation of source language cultural item there is two elements: one is descriptive and another one would be functional. Descriptive equivalent talks about size, color and composition. The functional equivalent talks about the purpose of the SL cultural-specific word.

5) Explanation as footnote:

The translator may wish to give extra information to the TL reader. He would explain this extra information in a footnote. It may come at the bottom of the page, at the end of chapter or at the end of the book.

6) Cultural equivalent: The SL cultural word is translated by TL cultural word

7) Compensation:A technique which is used when confronting a loss of meaning, sound effect, pragmatic effect or metaphor in one part of a text. The word or concept is compensated in other part of the text. 


\section{Conclusion}

To conclude, the first theory regarding cultural translation introduced by Mounin in 1963 who underlined the importance of the signification of a lexical item claiming that the best translation is the one which just the cultural items are correctly translated that only if this notion is considered will the translated item fulfill its function correctly. Nida in 1964 believed that differences between cultures may cause more severe complications for the translator than do differences in language structure. Regarding translation of cultural elements he paid more attention to dynamic equivalence which tries to relate the receptor to modes of behavior relevant within the context of his own culture without insisting that he understand the cultural patterns of the source-language context. The conclusion likely to be drawn from what Culler (1976) writes is that one of the troublesome problems of translation is the disparity among languages. The bigger the gap between the SL and the TL, the more difficult the transfer of message from the former to the latter will be.The difference between an SL and a $T L$ and the variation in their cultures make the process of translating a real challenge. Among the problematic factors involved in translation such as form, meaning, style, proverbs, idioms, etc., Newmark in 1988 categorized cultural words into Ecology (flora, fauna, hills, winds, plains); material Culture( food, clothes, houses and towns, transport); social Culture (work and leisure); organizations Customs, Activities, Procedures, Concepts (Political and administrative, religious ,artistic); gestures and habits. In 1992, Mona Baker believed that it is necessary for translator to have knowledge about semantics and lexical sets and the value of the words in source language. She mentioned that a translator can develop strategies for dealing with non-equivalence semantic field. These strategies are arranged hierarchically from general (superordinate) to specific (hyponym).

\section{References}

Baker, Mona (1992). In Other Words. London: Routledge.

Baker, Mona (2001). Routledge Encyclopedia of Translation Studies. London: Routledge.

Baker, Mona (2005). Translation and Conflict. London and New York: Routledge.

Bell, R. T. (1998). Psychological/cognitive approaches. In M. Baker (Ed), Routledge encyclopedia of translation studies. London \& New York: Routledge.

Culler, J. (1976). Structuralist poetics: structuralism, linguistics, and the study of literature. Cornell: Cornell University Press.

Graedler, A.L. (2000). Cultural shock. Retrieved December 6, 2006 from http://www.hf.uio.no/../top7culture.html

Harvey, M. (2003). A beginner's course in legal translation: the case of culture-bound terms.

H. Minabad, Hassan (2004). "Culture in Translation and Translation of Culture Specific Items".

Translation Studies. 5,2. : 31-46.

Lefevere, André (1992). Translation History Culture. London: Routledge.

Munday, Jeremy (2001). Introducing Translation Studies.

Newmark, P. (1988a). A Textbook of Translation. Hertfordshire: Prentice Hall.

Newmark, P. (1988b). Approaches to Translation. Hertfordshire: Prentice Hall.

Newmark, P. (1991). About Translation: Multilingual Matters. Clevedon, Philadelphia, Adelaide: Multilingual Matters Ltd

Nida, E. A. (1964). Towards a science of translation, with special reference to principles and procedures involved in Bible translating. Leiden: Brill.

Newmark, Peter (1981). Approaches to Translation. Oxford: Pregamon Press.

Venuti, L. (1998). Strategies of translation. In M. Baker (Ed.), Encyclopedia of translation studies (pp. 240-244). London and New York: Routledge. 